\section{Older patients with IBD might have higher risk of Parkinson's disease}

We read with interest the study by Villumsen et $a l^{1}$ which reported that patients with IBD had a $22 \%$ increased risk of Parkinson's disease (PD) compared with non-IBD individuals. The study supported the theory that intestinal environment could influence the function of central nervous system which was also called the gut-brain axis. Recently, a meta-analysis by Zhu et $a l^{2}$ suggested that the overall risk of PD in patients with IBD was significantly higher than controls (OR 1.41 ; $95 \%$ CI 1.19 to 1.66$)$. However, only four studies were included in the meta-analysis. We also noticed a casecontrol study by Camacho-Soto et $a l^{3}$ reporting that the risk of $\mathrm{PD}$ was inversely associated with IBD (OR $0.85 ; 95 \% \mathrm{CI}$ 0.80 to 0.91 ), which was not included in the meta-analysis by Zhu et al. ${ }^{2}$

To better understand this issue, we searched the PubMed and Web of Science for cohort and case-control studies investigating associations between IBD and risk of PD published before October 2018. Finally, five studies ${ }^{13-6}$ with totally 9174 766 participants were included, and we performed a meta-analysis with the software STATA V.12.0. The overall results showed that compared with reference individuals, patients with IBD did not have a significantly increased risk of PD (OR 1.19; $95 \%$ CI 0.93 to $\left.1.44 ; \mathrm{p}_{\text {heterogeneity }}<0.001\right)$, while the results with four cohort studies suggested that patients with IBD had significantly higher risk of PD (OR 1.26; 95\% CI 1.17 to $1.35 ; \mathrm{p}_{\text {heterogeneity }}=0.84$ ) (figure 1 ). Subgroup analysis for different classifications of IBD with all studies suggested that patients with UC or Crohn's disease (CD) did not have higher risk of PD, while the results with cohort studies showed that patients with UC or CD were associated
Study

ID
$\%$

OR $(95 \% \mathrm{Cl}) \quad$ Weight

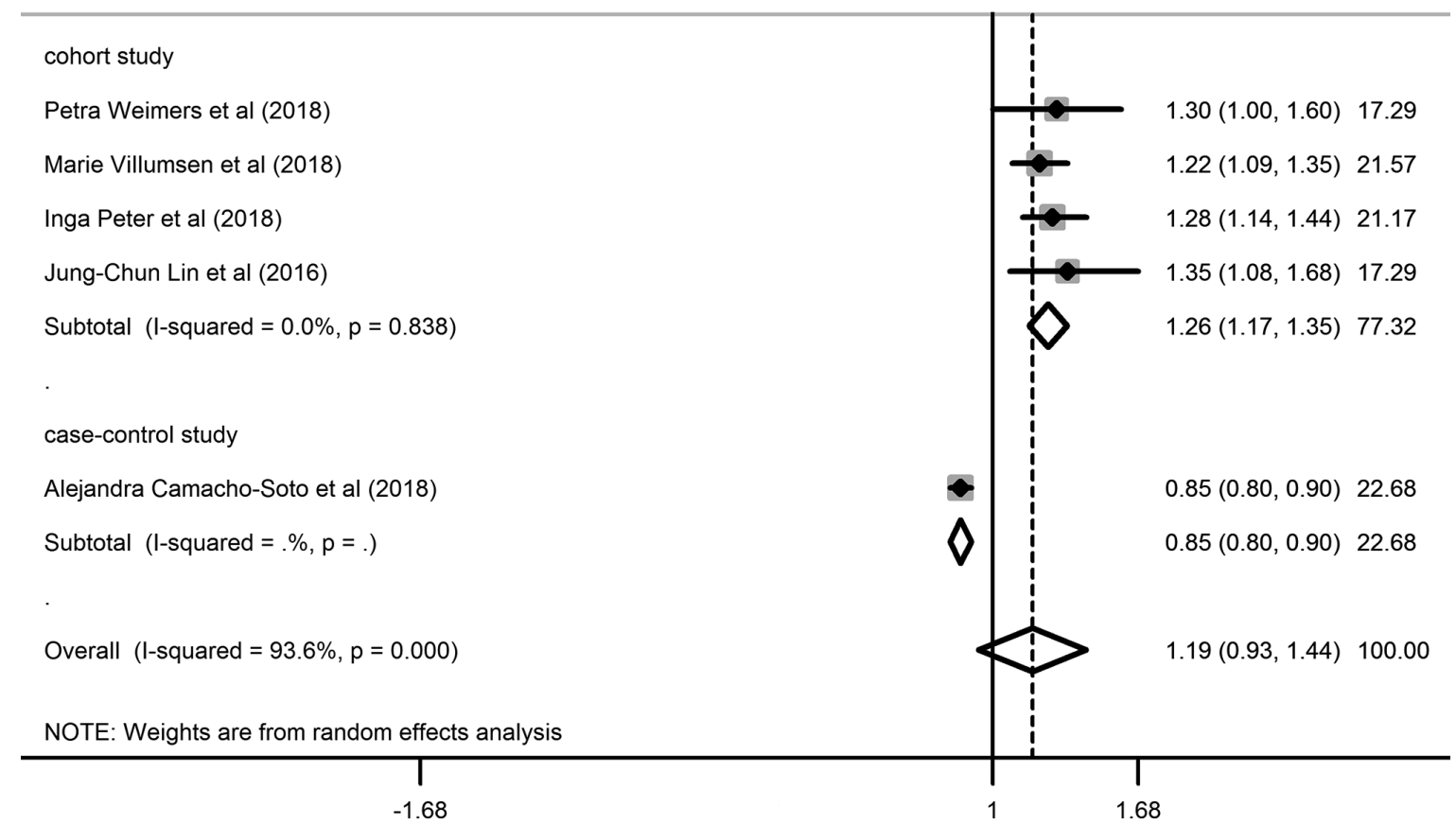

Figure 1 Forest plot of studies investigating associations between IBD and risk of Parkinson's disease. 


\begin{tabular}{|c|c|c|c|c|}
\hline Subgroup & Studies (n) & OR & $95 \% \mathrm{Cl}$ & $\mathbf{P}_{\text {heterogeneity }}$ \\
\hline \multicolumn{5}{|l|}{ UC } \\
\hline Cohort study & 3 & 1.29 & 1.13 to 1.45 & 0.58 \\
\hline Case-control study & 1 & 0.88 & 0.82 to 0.96 & - \\
\hline All studies & 4 & 1.12 & 0.81 to 1.42 & $<0.001$ \\
\hline \multicolumn{5}{|l|}{ Crohn's disease } \\
\hline Cohort study & 3 & 1.28 & 1.10 to 1.47 & 0.60 \\
\hline Case-control study & 1 & 0.83 & 0.74 to 0.93 & - \\
\hline All studies & 4 & 1.13 & 0.81 to 1.45 & $<0.001$ \\
\hline \multicolumn{5}{|l|}{ Age } \\
\hline$<50$ years old & 2 & 1.18 & 0.73 to 1.62 & 0.70 \\
\hline$\geq 60$ years old & 3 & 1.32 & 1.16 to 1.47 & 0.91 \\
\hline
\end{tabular}

with higher risk of PD (table 1). For the age at IBD diagnosis, we also found that patients with IBD in subgroup of ' $<50$ years old' were not associated with higher risk of PD. However, patients with IBD in subgroup of ' $\geq 60$ years old' had significantly increased risk of PD (OR 1.32; 95\% CI 1.16 to 1.47 ) (table 1).

Our meta-analysis showed that patients with IBD did no't have an increased risk of PD; however, subgroup analysis with cohort studies showed that they might be associated with increased risk of PD. PD is a multi-system disorder that occurs as a consequence of degeneration of dopaminergic and non-dopaminergic neurons, and the age has been regarded as an important risk factor for PD. ${ }^{7}$ In this study, we found that older patients with IBD had higher risk of PD which suggested that the age at IBD diagnosis might be a risk factor of PD. We also noticed that some studies presented the medication-associated side effects which resembled parkinsonism in the older population. ${ }^{8} 9$ Therefore, it is necessary to take it into consideration whether older people will take more medications, and whether these medications lead to a higher risk of PD also needs further studies to verify in the future.

In conclusion, based on the majority of included studies, patients with IBD, especially for those with later age, seemed to be associated with increased risk of PD. However, whether patients with IBD with younger age have higher risk of PD needs further well-designed observational studies to verify in the future.

\section{Qian-Yi Wan, Rui Zhao, Xiao-Ting Wu}

Department of Gastrointestinal Surgery, West China Hospital, Sichuan University, Chengdu, China

Correspondence to Professor Xiao-Ting Wu, Department of Gastrointestinal Surgery, West China Hospital, Sichuan University, Chengdu 610041, China; 2687183445@qq.com

Contributors Q-YW and RZ contributed equally in this study. Q-YW and RZ wrote the manuscript under the guidance of $X$-TW. All authors have read the manuscript and X-TW has approved the final manuscript.

Competing interests None declared.

Patient consent for publication Not required.

Provenance and peer review Not commissioned; externally peer reviewed. (c) Author(s) (or their employer(s)) 2020. No commercial re-use. See rights and permissions. Published by BMJ.

\section{(A) Check for updates}

To cite Wan Q-Y, Zhao R, Wu X-T. Gut 2020;69:193-194.

Received 1 July 2018

Revised 23 November 2018

Accepted 26 November 2018

Published Online First 5 December 2018

Gut 2020;69:193-194. doi:10.1136/ gutjnl-2018-317103

\section{REFERENCES}

1 Villumsen M, Aznar S, Pakkenberg B, et al. Inflammatory bowel disease increases the risk of Parkinson's disease: a Danish nationwide cohort study 1977-2014. Gut 2019:68:18-24.

2 Zhu F, Li C, Gong J, et al. The risk of parkinson's disease in inflammatory bowel disease: a systematic review and meta-analysis. Dig Liver Dis 2018.

3 Camacho-Soto A, Gross A, Searles Nielsen S, et al. Inflammatory bowel disease and risk of parkinson's disease in medicare beneficiaries. Parkinsonism Relat Disord 2018;50:23-8.

4 Weimers $\mathrm{P}$, Halfvarson J, Sachs MC, et al. Inflammatory bowel disease and parkinson's disease: a nationwide swedish cohort study. Inflamm Bowel Dis 2018

5 Peter I, Dubinsky M, Bressman S, et al. Anti-Tumor necrosis factor therapy and incidence of parkinson disease among patients with inflammatory bowel disease. JAMA Neurol 2018;75:939.

6 Lin JC, Lin CS, Hsu CW, et al. Association between parkinson's disease and inflammatory bowel disease: a nationwide taiwanese retrospective cohort study. Inflamm Bowel Dis 2016;22:1049-55.

7 van Rooden SM, Verbaan D, Stijnen T, et al. The influence of age and approaching death on the course of nondopaminergic symptoms in Parkinson's disease. Parkinsonism Relat Disord 2016:24:113-8

8 Prodan $\mathrm{Cl}$, Monnot M, Ross ED, et al. Reversible dementia with parkinsonian features associated with budesonide use. Neurology 2006;67:723.

9 Henriksen JN, Eriksson BO. Parkinsonism as a side effect of infliximab. BMJ Case Rep 2016;2016:bcr2016214802 